\title{
ACOSO SEXUAL: EL ESTADO DE LA CUESTIÓN EN ESPAÑA TRAS LOS ÚLTIMOS INSTRUMENTOS INTERNACIONALES*
}

\author{
Sexual harassment: the state of the matter in Spain after the \\ last international instruments \\ Assédio sexual: o estado da questão na Espanha após os \\ últimos instrumentos internacionais
}

\section{José Fernando Lousada Arochena ${ }^{a}$}

fernando.lousada@udc.es

Fecha de recepción: 07 de octubre de 2019

Fecha de revisión: 15 de octubre de 2019

Fecha de aceptación: 29 de enero de 2020

\section{RESUMEN}

El acoso sexual es una cuestión de actualidad, no porque antes no existiera, sino por su actual visibilización, identificación y protección jurídica, a raíz de las teorizaciones feministas acaecidas en la década de los setenta en los Estados Unidos de América. La teorización pasó a Europa, y en España, en 1989, fue contemplado legalmente. Actualmente, el derecho español contiene normas penales, laborales y administrativas dirigidas a la protección frente al acoso sexual. La aprobación del Convenio de Estambul en el ámbito del Consejo de Europa (2011) y, en el ámbito universal, de la Recomendación General 35 del CEDAW (2017) y del Convenio 190 de la OIT (2019), hace necesario su estudio con la finalidad de verificar si el derecho español se ajusta a las exigencias de estos instrumentos internacionales.

\section{PALABRAS CLAVE}

Acoso sexual; violencia de género; normativa internacional sobre acoso sexual; derecho español.

\footnotetext{
*Articulo de reflexión.

a. Magistrado especialista de lo social del Tribunal Superior de Justicia de Galicia. Doctor en Derecho con Premio Extraordinario. Profesor universitario de Derecho Procesal Civil y Penal. Participante en los trabajos de elaboración de la Ley Orgánica de Igualdad (2007). Colaborador con la Comisión de Igualdad del Consejo General del Poder Judicial. Copresidente de la Comisión de Igualdad de la Asociación Española de Derecho del Trabajo. Autor de libros, entre otros, sobre acoso sexual (1996), maternidad (2002), transversalidad de género (2007), conciliación masculina (2008), el derecho a la igualdad efectiva de mujeres y hombres (2014).
} 


\section{ABSTRACT}

Sexual harassment is a current topic, not because it did not existed before, but because of its present visibility, identification and judicial protection, as a consequence of the feminists theorizations that took place during the seventies in the United States of America. The theorization reached Europe, and in 1989 and it was legally established in Spain. At present, Spanish Law has criminal, working and administrative regulations for the purpose of protecting the victims of sexual harassment. The approval of the Istanbul Convention within the Council of Europe (2011) and, in the global framework of the General Recommendation 35 of CEDAW (2017) and the 190 Convention of ILO (2019) necessitates its study aimed at verifying if Spanish Law is in line with the standards of these international instruments.

\section{KEY WORDS}

Sexual harassment; gender violence; international norms on sexual harassment; Spanish Law.

\section{RESUMO}

0 assédio sexual é uma questão atual, não porque não existia antes, mas por sua visibilidade atual, identificação e proteção legal, como resultado de teorizações feministas na década de 1970 nos Estados Unidos da América. A teorização passou para a Europa e Espanha, onde, em 1989, foi legalmente contemplada. Atualmente, a legislação espanhola contém regras penais, trabalhistas e administrativas destinadas a proteger contra assédio sexual. A aprovação da Convenção de Istambul no Conselho da Europa (2011) e, no nível universal, da Recomendação Geral 35 da CEDAW (2017) e da Convenção 190 da OIT (2019) torna necessário estudá-la para verificar se a lei espanhola é de acordo com as exigências desses instrumentos internacionais.

\section{PALAVRAS-CHAVES}

Assédio sexual; violência de gênero; regras internacionais sobre assédio sexual; Lei espanhola.

\section{INTRODUCCIÓN: DESDE LA DESPROTECCIÓN HISTÓRICA DEL ACOSO SEXUAL A LA SITUACIÓN ACTUAL EN ESPAÑA}

Durante la mayor parte de la historia de la humanidad se ha considerado al acoso sexual ${ }^{1}$ como una conducta lícita e incluso socialmente aceptada (en sus formas más leves), o bien (en sus formas más graves) se castigaba como otro ilícito diferente cuando este se producía dentro de la dinámica del acoso sexual. Sin embargo, en ninguno de los casos anteriormente señalados la conducta se visibilizaba como acoso sexual. El acoso sexual solo se ha visibilizado como tal cuando se detecta que la discriminación contra las mujeres no obedece a las características físicas de su sexo, sino a los estereotipos sociales y culturales asociados a su sexo (esto es, el género) que, considerados en su conjunto, constituyen una superestructura ideológica legitimadora de la superioridad / dominación de los hombres, y complementariamente legitimadora de la inferioridad / sumisión de las mujeres, denominada sistema patriarcal, o patriarcado.

Como todo sistema de organización social que quiere imponerse sobre otras alternativas, evitando desviaciones, el sistema patriarcal necesita instrumentos de disuasión que pueden actuar beneficiando a quien se comporta dentro de los roles de género o sancionando a quienes los incumplen. Bajo esta perspectiva, la violencia de género es el instrumento de sanción por excelencia del sistema patriarcal. Sin embargo, la funcionalidad más profunda de la violencia de género en un sistema patriarcal es que por medio de su ejercicio se actualizan, en la realidad de la vida diaria, los estereotipos de dominación / sumisión asignados al hombre y a la mujer. La violencia de género es un fin en sí misma considerada. En cualquiera de sus manifestaciones, el hombre adopta una posición dominante, mientras la mujer es sometida, colocándose a ambos en la posición asignada por el sistema patriarcal.

1. Sobre el acoso sexual en la doctrina española, se pueden consultar los siguientes libros: Lousada Arochena, J. F., El derecho de los trabajadores a la protección frente al acoso sexual, Editorial Comares (Granada, 1996); Altés Tárrega, J. A., El acoso sexual en el trabajo, Editorial Tirant lo Blanch (Valencia, 2002); Pérez del Río, M. T., La violencia de género en el ámbito laboral: acoso sexual y acoso sexista, Editorial Bomarzo (Albacete, 2009); Rubio Castro, A. / Gil Ruíz, J. M., Dignidad e igualdad de derechos. El acoso en el trabajo, Editorial Dykinson (Madrid, 2012). 
Quizás el acoso sexual sea el mejor ejemplo de ese esquema teórico porque obedece no, como aparentemente se pudiera pensar, a las apetencias sexuales del agresor, sino a un estereotipo de entendimiento de la sexualidad, en el cual el hombre es el cazador (activo) y la mujer es la presa (pasiva). De esta manera se mantiene y se actualiza ese insensato estereotipo que, como toda la violencia de género, es un medio y a la vez un fin en sí mismo. A ello se añade que los estereotipos sexuales son un elemento fundamental del género, gracias a los cuales los hombres y las mujeres son tratados como "tales", de manera diferenciada. Por lo tanto, si el comportamiento sexual del hombre y la mujer es el definido por el estereotipo sexual de cada género, comprenderemos la directa conexión del acoso sexual, como una estructura de dominación, con la esencia del género.

Justamente esta conexión es la que explica que cualquier conducta de acoso sexual (incluso la más leve), está legitimando un sistema que las justifica al punto que aquellos que realizan las conductas más graves se sienten legitimados por quienes cometen las más leves. Quien comete cualquier conducta de acoso sexual (incluso la más leve) está apoyando ese sistema de dominación, sabiéndolo o debiéndolo saber. Esa legitimación general del sistema de dominación lo perciben las propias víctimas a través de la incomprensión de la sociedad hacia su situación personal como acosadas, generando una victimización secundaria que, en ocasiones, conducen al suicidio de la víctima o, en casos menos graves, incapacidades laborales temporales o permanentes.

Por todo ello, el acoso sexual se pudo visibilizar al elaborarse el concepto de género por las feministas estadounidenses en los años setenta. La elaboración doctrinal más sólida, la de Catharine MacKinnon, sostiene que el acoso sexual no es cuestión de sexualidad, pues ello ignora la substancia del significado social de pertenecer al sexo femenino, por el cual en gran medida se define a una persona como perteneciente a dicho sexo desde la perspectiva de su sexualidad. Por lo tanto, el acoso sexual ocurre no porque la acosada es una persona, sino porque es una mujer. En el ámbito laboral, el acoso tiene lugar principalmente porque las mujeres ocupan posiciones y funciones laborales inferiores; esta situación, al mismo tiempo, coadyuva a mantenerlas en tales posiciones. En suma, se crean dos normas para el empleo: una para mujeres, comprensiva de exigencias sexuales, y otra, para hombres, sin ellas ${ }^{2}$.

Vía judicial o vía legislativa, el reconocimiento jurídico positivo de esas aportaciones doctrinales tuvo sus primeras cristalizaciones en los Estados Unidos, a través de los reglamentos de la Equal Employment Opportunities Comission, $1980^{3}$, y de la jurisprudencia del Tribunal Supremo desde $1986^{4}$. Muy pronto la teorización pasó a Europa ${ }^{5}$ en donde, ya desde mediados de los años ochenta, el acoso sexual fue reconocido como ilícito en la doctrina judicial del Reino Unido. Por su lado, las primeras leyes sobre acoso sexual fueron aprobadas en España (Ley 3/1989, de 3 de marzo, absolutamente pionera en la materia ${ }^{6}$ ), en Suecia (Ley de 30 de mayo de 1991), en Bélgica (Decreto de 18 de septiembre de $1992^{7}$ ), en Francia (Ley 92-1179, de 2 de noviembre de 1992), y en

2. MacKinnon, C., Sexual harassment of working women, Yale University Press (New Haven and London, 1979), pp. 9, 147 y 193, passim.

3. La Equal Eployment Opportunities Comission ha regulado el acoso sexual laboral en la Sección 1604.11 del Título 29 del Código de Reglamentaciones Federales (Código Electrónico de Regulaciones Federales).

4. Caso Meritor Savings Bank vs Vinson, 477 US 57 (1986) Mechelle Vinson acusó al vicepresidente del Banco de Ahorros Meritor de haberla forzado a tener relaciones sexuales entre 40 y 50 veces, aunque no había pérdida tangible de derechos laborales. El Tribunal Supremo, de manera unánime, considera el acoso sexual discriminación sexista aunque no haya tal pérdida siempre que sean conductas graves o frecuentes, que han creado un ambiente hostil o abusivo, no han sido bien recibidas y están basadas en el sexo de la víctima.

5. Son especialmente interesantes las aportaciones de autoras feministas francesas que, realizando investigaciones históricas sobre la situación de las obreras en los Siglos XIX y XX, consideraron el acoso sexual como una reminiscencia en las sociedades industriales del derecho de pernada medieval. Vease en esa línea de investigación Louis, M.V., Le droit de cuissage: France 1860-1930, Editions de l'Atelier (París, 1984).

6. La introducción del acoso sexual en la Ley 3/1989, de 3 de marzo, fue valorada positivamente, en especial, porque, al entroncar su protección en el derecho a la dignidad e intimidad reconocido como fundamental en el artículo 18 de la CE, se aplicaba al acoso la tutela de los derechos fundamentales; se le criticó la falta de una definición que distinga chantaje y acoso ambiental, de su consideración como discriminación sexista, y de mecanismos de prevención (Escudero Rodríguez, R., "La Ley 3/1989. Una reforma promocional de la mujer con acentuados claroscuros", Relaciones Laborales, Tomo Segundo, 1989, p. 1148 Pérez del Río, T., "El acoso sexual en el trabajo: su sanción en el orden social", Relaciones Laborales, Tomo Segundo, 1990, p. 183; Del Rey Guanter, S., "Acoso sexual y relación laboral", Relaciones Laborales, Tomo Primero, 1993, p. 233).

7. Para un comentario de esta norma, véase Jacqmain, J., Harcèlement sexuel sûr le liux de travail: les moyens d'action juridiques en droit du travail, Ministerio de Empleo y Trabajo (Bruselas, 1992). 
Alemania (Ley sobre Igualdad de Hombres y Mujeres, de 24 de junio de 1994) ${ }^{8}$.

En el ámbito de las Comunidades Europeas, la preocupación por el acoso sexual se entronca con la igualdad de los sexos desde su primera referencia en la Resolución de 11.6.1986 del Parlamento Europeo, sobre agresiones a la mujer. A instancia de esa resolución surgió el Informe sobre el problema del acoso sexual en los Estados Miembros de las Comunidades Europeas, elaborado por el experto Michael Rubenstein'. $Y$ ese Informe inspira la Recomendación de 27.11.1991 de la Comisión de las Comunidades Europeas, relativa a la protección de la dignidad de la mujer y del hombre en el trabajo, incorporando, en su Anexo, el Código de Conducta para combatir el acoso sexual, con el cual se busca proporcionar una orientación práctica para empresarios, sindicatos y trabajadores acerca de la protección de la dignidad de mujer y hombre en el trabajo.

Todavía se esperó más de diez años para aprobar una norma comunitaria vinculante en la materia: la Directiva 2002/73/CE, del Parlamento Europeo y del Consejo, de 23 de septiembre de 2002, sobre asuntos de empleo y ocupación ${ }^{10}$, que define el acoso sexual, lo considera discriminatorio, y establece la obligación de alentar a empresarios y responsables del acceso a la formación a adoptar medidas para la prevención (disposiciones refundidas en los actuales artículos 2.1.d, 2.2.a y 26 de la Directiva 2006/54/CE del Parlamento Europeo y del Consejo de 5 de julio de 2006, Directiva refundición). A su vez, la Directiva 2004/113/CE del Consejo, de 13 de diciembre de 2004, por la que se aplica el principio de igualdad de trato entre hombres y mujeres al acceso a bienes y servicios, y su suministro, también

8. Un análisis de derecho comparado de los años noventa del siglo pasado, Husbands, R., "Análisis internacional de las leyes que sancionan el acoso sexual", Revista Internacional del Trabajo, volumen 112, número 1, 1993, y Aeberhard-Hodges, J., "Jurisprudencia reciente sobre el acoso sexual en el trabajo", Revista Internacional del Trabajo, volumen 115, número 6, 1996.

9. Rubenstein, M., Informe sobre el problema del acoso sexual en los Estados miembros de las Comunidades Europeas, Oficina de Publicaciones Oficiales de las Comunidades Europeas (Luxemburgo, 1988).

10. Sobre esta Directiva, Lousada Arochena, J.F., "El principio de transversalidad en el ámbito de las relaciones laborales (Un comentario de la Directiva 2002/73/CE, de 23 de septiembre de 2002)" Relaciones Laborales, Tomo Segundo, 2003; y Jacqmain, J., "L'égalité entre femmes et hommes dans les conditions de travail: amendements à la directive européenne 76/207", Contrats de Travail, número 276, Bruselas-Bélgica, 2003. contempla el acoso sexual dentro de su ámbito de aplicación (arts. 2.d y 4.3).

Ya antes de la Directiva 2002/73/CE, España disponía, desde 1989, de una regulación laboral (Estatuto de los Trabajadores, art. 4.2.e: la protección frente al acoso sexual es un derecho de las personas trabajadoras en la relación de trabajo) y en el empleo público (Estatuto Básico del Empleado Público, art. 14.h: la protección frente al acoso sexual es un derecho de los funcionarios/as públicos en la relación de servicio), y, desde 1995, de carácter penal para las conductas más graves (Código Penal, art. 184). Tras la Directiva 2006/54/CE, se ha traspuesto, a través de la Ley Orgánica 3/2007, de 22 de marzo, para la igualdad efectiva de mujeres y hombres, la definición de acoso sexual de dicha Directiva (art. 7.1), lo califica de discriminatorio (art. 7.3), y asimismo recoge mecanismos para prevenirlo en el empleo privado (art. 48) y en el empleo público (art. 62).

La aprobación con posterioridad a la LO Igualdad de tres instrumentos internacionales que contemplan el acoso sexual exige su análisis para verificar si el aparato normativo español es acertado y suficiente, o si precisa correcciones y debe ser completado.

El primero en el tiempo es el Convenio del Consejo de Europa sobre prevención y lucha contra la violencia contra las mujeres y la violencia de género que se firmó el 11 de mayo de 2011 en Estambul, ratificado por España (en vigor desde el 1 de enero de 2014) ${ }^{11}$.

El segundo es la Recomendación General 35 del Comité para la eliminación de todas las formas de discriminación contra la mujer (CEDAW, por su acrónimo en inglés, aprobada el 26 de julio de 2017), sobre la violencia por razón de género contra la mujer, por la que se actualiza la Recomendación General 19.

El tercero, es el Convenio número 190 sobre violencia y acoso en el trabajo, aprobado el 21 de junio de 2019 por la Conferencia Internacional

11. Sobre este Convenio, vease Gil Ruíz, J. M. (ed.), El Convenio de Estambul como marco de derecho antisubordiscriminatorio", Editorial Dykinson (Madrid, 2018); en particular sobre el acoso sexual vease la aportación de Lousada Arochena, J. F., "El acoso sexual en el Convenio de Estambul y su transposición interna: El Pacto de Estado en materia de Violencia de Género", pp. 71-100. 
del Trabajo, y acompañado de la Recomendación número 206 (cuyas disposiciones complementan y se considerarán conjuntamente con las del Convenio), que, por su reciente aprobación, aún no ha sido ratificado por España (de hecho, no lo ha sido todavía por ningún otro Estado).

\section{EL ACOSO SEXUAL EN EL CONVENIO DE ESTAMBUL}

El Convenio de Estambul establece, en su artículo 40, lo siguiente:

\footnotetext{
"Las Partes adoptarán las medidas legislativas o de otro tipo necesarias para que toda forma de comportamiento no deseado, verbal, no verbal o físico, de carácter sexual, que tenga por objeto o resultado violar la dignidad de una persona, en particular cuando dicho comportamiento cree un ambiente intimidatorio, hostil, degradante, humillante u ofensivo, sea castigado con sanciones penales u otro tipo de sanciones legales".
}

Se trata de una definición claramente inspirada (y es un dato que conviene retener) en el artículo 2.1.d de la antes citada Directiva 2006/54/ CE (y en el paralelo artículo 2.d de la también antes citada Directiva 2004/113/CE), donde el acoso sexual aparece definido en los siguientes términos:

"La situación en que se produce cualquier comportamiento verbal, no verbal o físico no deseado de índole sexual con el propósito o el efecto de atentar contra la dignidad de una persona, en particular cuando se crea un entorno intimidatorio, hostil, degradante, humillante $\mathrm{u}$ ofensivo".

\subsection{El presupuesto de hecho del acoso sexual}

A la vista del artículo 40 del Convenio de Estambul, el acoso sexual se puede definir como "toda forma de comportamiento no deseado, verbal, no verbal o físico, de carácter sexual, que tenga por objeto o resultado violar la dignidad de una persona, en particular cuando dicho comportamiento cree un ambiente intimidatorio, hostil, degradante, humillante u ofensivo". De este concepto se derivan los siguientes elementos típicos:

(I) Toda forma de comportamiento verbal, no verbal o físico: chantaje sexual y acoso ambiental. La fórmula genérica utilizada en el artículo 40 del Convenio de Estambul comprende comportamientos verbales: requerimientos de favores sexuales con promesas explícitas o implícitas de un trato preferencial, o con amenazas en caso de no acceder; abuso del lenguaje con comentarios ofensivos sobre la apariencia o el aspecto; bromas de mal gusto, invitaciones comprometedoras $\mathrm{u}$ observaciones desagradables o sugerentes hacia la persona receptora. Igualmente trata comportamientos no verbales o físicos: contacto físico de carácter sexual; gestos ofensivos; exhibición de material pornográfico en el lugar de trabajo; observación camuflada de personas en aseos u otros espacios reservados, directamente o a través del uso de un circuito cerrado de televisión.

Debería conjurar la referencia normativa a "toda forma de comportamiento" cualquier interpretación tendente a exigir, para la existencia de un acoso sexual, la reiteración de conductas. Naturalmente, la reiteración de conductas facilita la calificación de la conducta como acoso sexual, así como su prueba. Pero dentro del concepto también cabe el acoso sexual sin apreciar la existencia de reiteración de conductas. Obviar esta conclusión sería tanto como revivir en el ámbito del acoso sexual laboral el problema, afortunadamente superado en el ámbito de la violencia en la pareja, de que las formas de discriminación y/o violencia contra las mujeres suelen ser banalizadas y consideradas en sí mismas poco graves, de ahí se exigiese la reiteración, la habitualidad o la permanencia ${ }^{12}$.

Sobre la consideración de esta amplitud de los comportamientos de acoso sexual se debe incluir el chantaje sexual y el acoso ambiental como formas típicas de acoso sexual.

El chantaje sexual o acoso sexual de intercambio, denominado "quid pro quo", se produce cuando el sujeto activo del acoso sexual ostenta una posición de poder formal sobre el sujeto pasivo dentro de una concreta relación jurídica (los supuestos más típicos se producen en la relación laboral, funcionarial o de servicio, en la docencia y en la relación arrendaticia, pero obviamente no estamos ante un elenco cerrado), y condiciona el ejercicio de ese poder formal (en

12. Rubio Castro, A. / Gil Ruíz, J. M., Diginidad ..., obra citada, pp. 168 ss. 
el acoso laboral, se condiciona el acceso al empleo, una condición laboral o el cese del trabajador) a la realización de un acto de contenido sexual.

Por consiguiente, solo puede ser sujeto activo de un chantaje sexual quien ostenta esa posición de poder formal que, en el acoso laboral, sería el empresario físico, el representante legal del empresario jurídico o un directivo con competencia delegada para decidir el acceso al empleo, una condición laboral o el cese del trabajador. Habitualmente, está orientado a la realización de algún acto carnal, pero se puede orientar a otras ofensas sexuales, un ejemplo es la imposición al personal femenino de un uniforme sexualmente provocativo.

Por su forma, los actos de chantaje sexual pueden ser explícitos, directos o expresos, bien buscando conseguir el consentimiento (viciado) de la víctima -como es el caso de la proposición o solicitud sexual-, bien prescindiendo de conseguir ese consentimiento -como es el caso del requerimiento sexual, con o sin compulsión física, o la directa imposición de condiciones sexuales-. Por otro lado, el chantaje implícito, indirecto o tácito, se produce cuando la víctima nunca ha sido solicitada o requerida sexualmente, pero otras personas de su mismo sexo y en idénticas circunstancias reciben ventajas por aceptar las condiciones de un chantaje sexual, incitando a la aceptación por parte de la víctima.

Por sus efectos, el chantaje sexual puede conllevar o no una pérdida tangible de derechos dentro de la relación jurídica de que se trate. Aunque no sea lo habitual, el chantaje sexual puede no conllevar dicha pérdida cuando, a pesar de la negativa de la víctima, el sujeto activo del chantaje sexual no cumple su amenaza, o en el chantaje implícito, donde, más que pérdida de derechos, lo que hay es una no adquisición o una pérdida de expectativas. Sin embargo, lo habitual es, en los casos de chantaje, la pérdida tangible de derechos dentro de la relación jurídica de que se trate, como represalia a la negativa de la víctima. Realmente, el ilícito, en este supuesto, se duplica, siendo ilícito, de un lado, el chantaje sexual y, de otro lado, la pérdida tangible de derechos de la víctima.

El acoso ambiental se produce cuando el comportamiento del sujeto activo del acoso sexual, que puede ser solo una persona o todo un grupo más o menos identificado, determina la violación de la dignidad de una persona dentro de una concreta relación jurídica o sin referencia alguna a una concreta relación jurídica. De este modo, se multiplican los sujetos activos dentro de la concreta relación jurídica (por ejemplo, en el acoso sexual laboral, pueden ser sujetos activos compañeros de trabajo, o terceras personas ajenas a la relación laboral que interactúan con la víctima con ocasión de la relación laboral: acoso de terceros). Cuando el acoso ambiental se produce sin referencia a una concreta relación jurídica, cualquiera puede ser sujeto activo, incluso personas extrañas a la víctima o que, aunque puedan ser conocidas, no mantienen con la víctima una relación jurídica o social relevante (por ejemplo, un viejo compañero de estudios, un vecino con el que no hay mayor relación, o alguien con el que se tropieza en la calle y que luego la persigue). Igualmente las conductas ofrecen una mayor variedad, ya que tanto pueden ser las mismas definidas de chantaje si no median condicionantes, como otras conductas (por ejemplo, las ofensas verbales, incluso bromas, piropos ofensivos, o comentarios sobre la apariencia).

Si el acoso sexual ambiental se produce dentro de una relación laboral, funcionarial o de servicio, se puede distinguir entre acoso vertical descendente (de superior jerárquico a trabajador/a subordinado, supuesto muy habitual al acumularse el poder informal de género con el poder formal derivado de la organización de la empresa), acoso vertical ascendente (de trabajador/a subordinado a superior jerárquico, supuesto muy excepcional pero que resulta factible en cuanto el poder informal de género puede subvertir el poder formal derivado de la organización de la empresa), acoso horizontal (entre personas sin ninguna relación jerárquica), $\mathrm{y}$ acoso mixto (cuando la superioridad, lo que determina la existencia de un acoso descendente, incita al acoso de la víctima por otros compañeros de trabajo, lo que determina la existencia de un acoso horizontal). Mientras el acoso sexual ambiental admite todas estas modalidades, el chantaje sexual es siempre acoso descendente.

Ahora bien, la inclusión de cualesquiera conductas en el ámbito de protección no significa ni linealidad de supuestos fácticos ni uniformidad en su protección, pues el acoso sexual abarca supuestos muy distintos, y la protección de cada 
uno dependerá del comportamiento de que se trate y de las circunstancias en las cuales se manifieste. El comportamiento de que se trate tiene diferente gravedad según si se trata de una agresión física, de un chantaje sexual, de una solicitud sexual o de la sumisión a un acoso ambiental sin requerimiento ni solicitud. La reiteración, habitualidad o permanencia del comportamiento no es exigida para hablar de acoso sexual, pero cuando concurran sí que conllevará siempre una mayor gravedad. También las circunstancias en las cuales se manifieste el comportamiento son decisivas para acabar de definir la gravedad del supuesto.

(II) No deseado. Al momento de concretar el elemento antijurídico en el acoso sexual, se puede utilizar exclusivamente un estándar de carácter subjetivo (según el cual sería acoso sexual un comportamiento de carácter sexual no deseado en cuanto la víctima se ha opuesto al comportamiento: si no fuera no deseado no sería acoso aun si se pudiera catalogar objetivamente de ofensivo), o se puede utilizar exclusivamente un estándar de carácter objetivo (según el cual sería acoso sexual un comportamiento de carácter sexual ofensivo: si no fuera objetivamente ofensivo no sería acoso aun si fuera no deseado).

Utilizar exclusivamente el estándar subjetivo en la definición aparenta ser una respuesta positiva frente al acoso sexual al dejar decidir a la persona receptora del comportamiento lo que es acoso sexual y lo que no es acoso sexual. De este modo, un acto en principio ofensivo no sería acoso si es bien recibido por la persona receptora del comportamiento. Y a la inversa, un acto en principio inofensivo sería acoso si es mal recibido por la persona receptora del comportamiento. Sería, en consecuencia, la persona receptora del comportamiento la que libre y voluntariamente definiría hasta donde puede llegar un comportamiento sin constituir acoso sexual y desde donde sería acoso sexual.

Pero las anteriores consideraciones se realizan como si en efecto las mujeres vivieran con igual libertad que los hombres. Y es que la propia dinámica de la exigencia impone a la persona receptora del comportamiento, si ha sufrido o prevé va a sufrir un acto de acoso sexual, la carga de decir no, con lo cual se desprotegería a aquellas mujeres que no dicen que no bien porque aceptan su rol de sumisión en una sociedad patriarcal o bien porque, aún no aceptándolo, no quieren enfrentarse. Muchas veces además el acoso sexual se produce en el contexto de una relación jurídica en la cual ya existe una situación de subordinación de la víctima (por ejemplo, un acoso laboral, un acoso en una relación de servicio o un acoso arrendaticio), lo cual determina una menor predisposición a manifestar una negativa incluso si la víctima es un hombre, pero mayormente si se trata de una mujer.

No bastaría tampoco con decir que no para que un comportamiento pasado se pudiera considerar como no deseado, pues obviamente dicha negativa solamente tendría efectos de futuro, de modo que los comportamientos anteriores a la negativa, aunque se tratase de comportamientos calificables de ofensivos, no constituirían acoso sexual y solo lo constituirían, si en efecto se produjeren, aquellos que sean posteriores a la negativa.

Y únase a todo ello que, en caso de llegar a juicio, la persona receptora del comportamiento debería acreditar la negativa, lo que no siempre es fácil dado que estos comportamientos se suelen producir en contextos privados preordenados por el agresor.

Buscando evitar los inconvenientes más llamativos del no deseado que conducirían al muy criticable resultado de exigir un no rotundo de la víctima para la existencia de un acoso sexual, la jurisprudencia y la doctrina entienden que, existiendo una conducta objetivamente ofensiva, se debe presumir que esta es no deseada, de modo que a la persona demandante o denunciante le bastaría con acreditar una conducta ofensiva, mientras a la persona demandada o denunciada le correspondería, en su caso, acreditar el carácter deseado que excluiría la ilicitud; o, dicho más sencillamente, que hubo consentimiento.

(III) De carácter sexual. El carácter sexual nos conduce tanto a conductas dirigidas a la realización de un acto carnal (conductas libidinosas), como a otras conductas que, aunque no se dirigen a la realización de un acto carnal, son obscenas o impropias al introducir un elemento sexual en un contexto que es inapropiado (por ejemplo, la utilización de pornografía en el trabajo, o las bromas de mal gusto). Analizadas sin mayor profundidad, su motivación es diferente al acoso sexista (que existiría, por ejemplo, despidiendo a 
trabajadoras por motivos misóginos, o por razon de su maternidad). No obstante, la diferencia entre lo sexual y lo sexista tiende a diluirse cuando se analiza la cuestión desde una perspectiva de género porque los estereotipos de género, sean sexuales o sexistas, interactúan, incluso en los supuestos más claros de agresión sexual (por ejemplo, una violación no es tanto cuestión de sexualidad como de reafirmación del poder del hombre sobre la mujer) o de acoso sexista (por ejemplo, la misoginia o la discriminación por maternidad se sustentan en prejuicios), hasta el extremo de que en las más de las ocasiones se mezclan en la realidad de las cosas lo sexual y lo sexista (por ejemplo, los comentarios obscenos sobre la apariencia física de una mujer resultan a la vez sexuales y sexistas; además normalmente esos comentarios se suelen acompañar de avances sexuales).

(IV) Que tenga por objeto o resultado violar la dignidad de una persona, en particular cuando dicho comportamiento cree un ambiente intimidatorio, hostil, degradante, humillante u ofensivo. Entendemos que hay una violación de la dignidad de una persona cuando el acosador debe saber, o sabe, que su comportamiento es ofensivo. Esto supone incluir en el concepto legal de acoso sexual dos clases de comportamientos ${ }^{13}$ :

(a) Aquellas conductas que el acosador, aunque nada le manifestara la víctima acerca de su rechazo al comportamiento, debiera saber que son ofensivas en atención a su gravedad (realizando al respecto un juicio objetivo sobre valores constitucionales, y en ningún caso un juicio de moralidad), y a las circunstancias concurrentes (de tiempo y lugar, así como de condición de las diferentes personas intervinientes), de las cuales dos circunstancias eventualmente concurrentes destacan por su habitual conflictividad práctica:

- la actuación previa de la víctima, que puede ser relevante cuando haya un consentimiento a la aproximación sexual claramente manifestado o una insinuación de contenido inequívoco en el mismo sentido (apreciando ello con criterios

13. Lousada Arochena, J. F., El derecho ..., obra citada, pp. 105 a 112. Más concretamente, Lousada Arochena, J. F., "El concepto de acoso sexual laboral según la Sentencia de 13 de diciembre de 1999 del Tribunal Constitucional", Relaciones Laborales, número 3, 2000. También aceptan el estándar mixto Pérez del Río, T., La violencia ..., obra citada, pp. 34 y 35; y Rubio Castro, A. / Gil Ruíz, J. M., Dignidad ..., obra citada, p. 132. objetivos ponderando la situación real de la víctima y nunca con el criterio subjetivo del acosador); $y$

- la existencia de una previa relación sexual consentida, en cuyo caso es razonable exigir (frente a la regla general de no obligar a la víctima a decir que no) la previa negativa expresa de quien la rompe para poder hablar de un posterior acoso sexual (salvo si se tratase de una aproximación sexual con un componente coactivo especialmente fuerte).

(b) Aquellas conductas que el acosador, aunque no se puedan considerar como ofensivas en atención a su gravedad y circunstancias concurrentes, sabe que son ofensivas para la víctima porque aquella lo manifestó expresamente o mediante actuación de contenido inequívoco. Por ejemplo, una mirada, aún de cierta persistencia, no es objetivamente ofensiva, pero, si a su receptor/a le es molesta y así se lo manifiesta al emisor/a, su reiteración resultaría antijurídica y sería constitutiva de un acoso sexual.

En ninguno de los casos es necesaria la intención de violación de la dignidad de la víctima, pues aunque no haya ese "propósito" basta con que se produzca ese "resultado". Si el acoso sexual es notoriamente grave en términos objetivos (pensemos, por ejemplo, en tocamientos físicos en zonas erógenas), seguramente siempre estaríamos ante el propósito de atentar contra la dignidad de la persona (dado que se hace casi imposible imaginar que en esos casos pueda haber un propósito diferente). Pero si no lo es (y sin descartar que en estos casos también puede haber en última instancia ese propósito, pero que no es necesario acreditarlo) podríamos estar ante un resultado de atentar contra la dignidad de la persona aunque el propósito sea aparentemente otro diferente (por ejemplo, una intención supuestamente romántica, paternalista, halagadora o jocosa). De esta manera, las intenciones supuestamente legítimas que el acosador o su entorno utilizan para justificar su conducta decaen cuando el resultado se muestra atentatorio de la dignidad de la persona.

Una última consideración se deriva del inciso final contenido en la definición: "en particular cuando se crea un entorno intimidatorio, hostil, degradante, humillante u ofensivo". Este inciso final está pensando en el acoso ambiental, dejando claro que es acoso sexual, aunque no lo 
contrapone con el chantaje sexual. De este modo, comportamientos cuyo propósito o resultado sea la violación de la dignidad de las personas con difícil encanje en alguna de esas dos categorías pueden ser acoso sexual. Ciertamente, en el ámbito de la relación laboral o de otra relación jurídica contextual no es fácil imaginar atentados contra la dignidad de las personas que no sean ni chantaje sexual ni acoso ambiental. Pero fuera de una concreta relación jurídica contextual es más fácil imaginar atentados contra la dignidad de las personas que, sin ser chantaje sexual (imposible al no existir una concreta relación jurídica contextual), tampoco se pueda considerar que creen un entorno intimidatorio, hostil, degradante, humillante $\mathrm{u}$ ofensivo a causa del comportamiento individualizado de persona 0 personas perfectamente identificadas. Todo lo cual permite concluir que la definición de acoso sexual contenida en el artículo 40 del Convenio de Estambul está incluyendo comportamientos tales como el acoso callejero que pueden sufrir las mujeres provenintes de un colectivo de hombres sin una relación entre sí.

\subsection{Las consecuencias jurídicas consiguientes al acoso sexual}

A la vista del artículo 40 del Convenio de Estambul, el acoso sexual, tal como este lo define, será "castigado con sanciones penales u otro tipo de sanciones legales", es decir que cabe su sanción solo con sanciones penales, solo con otras sanciones legales (típicamente las sanciones administrativas), o con ambas cosas (sanciones penales para las conductas más graves; otras sanciones legales para las demás conductas).

Podemos aquí observar una diferencia muy importante con las demás manifestaciones de violencia de género del Convenio de Estambul, pues todas ellas, si intencionadas, se deben castigar con sanciones penales: la violencia psicológica (art. 33); el acoso (art. 34); la violencia física (art. 35); la violencia sexual con inclusión de la violación (art. 36); los matrimonios forzosos (art. 37); las mutilaciones genitales femeninas (art. 38); y el aborto y la esterilización forzosa (art. 39).

También a diferencia de algunas otras manifestaciones de violencia de género, los Estados Parte, en relación con el acoso sexual, no están obligados a castigar penalmente la asistencia y la complicidad intencionada (art. 41.1), ni la tentativa intencionada (art. 41.2). Igualmente se excluye al acoso sexual de ciertas especificaciones dirigidas a garantizar la extensión de la competencia judicial extraterritorial (arts. 44.3 y $4^{14}$ ); no resulta obligada la tramitación de oficio (art. 55 $5^{15}$ ); ni retrasar el cómputo de la prescripción hasta la mayoría de edad (art. 58 ${ }^{16}$ ); ni adoptar ciertas medidas para personas en situaciones de riesgo (art. 63 ${ }^{17}$ ).

Se aplicarán en lo demás todas las disposiciones contempladas en el Convenio de Estambul. En particular, las disposiciones comunes de prevención de la violencia de género en las que se imponen a los Estados Parte obligaciones generales y obligaciones específicas.

Las obligaciones generales obligan a las Partes a tomar todas las medidas necesarias para (1) promover los cambios en los modos de comportamiento socioculturales de las mujeres y los hombres con vistas a erradicar los prejuicios, costumbres, tradiciones y cualquier otra práctica

14. Los Estados Parte, en relación con determinadas manifestaciones de violencia de género entre las cuales no se encuentra el acoso sexual, no pueden subordinar la competencia judicial ni a la condición de que los hechos también estén tipificados en el territorio en el que se hayan cometido (véase el art. 44.3), ni a la condición de que la apertura de diligencias venga precedida de una demanda de la víctima o de una denuncia de Estado del lugar en el que el delito haya sido cometido, cuando el hecho se hay a cometido por uno de sus nacionales, o por persona que tenga residencia habitual en su territorio (véase el art. 44.4).

15. Los Estados Parte, en relación con determinadas manifestaciones de violencia de género entre las cuales no se encuentra el acoso sexual, velarán por que las investigaciones o procedimientos no dependan totalmente de una denuncia o demanda de la víctima cuando el delito se hubiera cometido, en parte o en su totalidad, en su territorio, y por que el procedimiento pueda continuar su tramitación incluso cuando la víctima se retracte o retire su denuncia en relación con el delito de violencia de género (véase el art. 55).

16. Los Estados Parte, en relación con determinadas manifestaciones de violencia de género entre las cuales no se encuentra el acoso sexual, adoptarán las medidas legislativas o de otro tipo necesarias a efectos de que el plazo de prescripción para instar un procedimiento tenga una duración que sea suficiente y proporcional a la gravedad de el delito de que se trate, a fin de permitir la tramitación eficaz del procedimiento, después de la fecha en que la víctima haya adquirido la mayoría de edad (véase el art. 58).

17. Cuando una de las Partes, sobre la base de la información que posea, tenga serios motivos para creer que una persona corre el riesgo de quedar sometida de modo inmediato en el territorio de otra Parte a determinados actos de violencia entre los cuales no se encuentra el acoso sexual, se anima a la Parte que disponga de la información a transmitirla sin demora a la otra Parte con el fin de asegurarse de que se toman las medidas protección apropiadas. Esta información deberá contener, en su caso, indicaciones acerca de las disposiciones de protección existentes a favor de la persona en peligro (véase el art. 63). 
basada en la idea de la inferioridad de la mujer o en un papel estereotipado de las mujeres y los hombres; (2) prevenir todas las formas de violencia incluidas en el ámbito de aplicación del Convenio de Estambul, (3) animar a todos los miembros de la sociedad, en particular los hombres y los niños, a contribuir activamente a la prevención de todas las formas de violencia incluidas, (4) velar por que no se considere que la cultura, las costumbres, la religión, la tradición o el supuesto honor justifican actos de violencia, y (5) promover programas y actividades para la autonomía de las mujeres.

Las específicas (en cuyo detalle no entraremos, invitando al lector o lectora a su lectura directa) se refieren a sensibilización (artículo 13), educación (artículo 14), formación de profesionales (artículo 15), programas preventivos de intervención y tratamiento (artículo 16), y participación de sector privado y medios de comunicación (artículo 17).

Todas las medidas (incluyendo tanto las generales como las específicas) tendrán en cuenta las necesidades específicas de las personas vulnerables debido a circunstancias particulares, y pondrán en su centro los derechos humanos de las víctimas (artículo 12).

\section{EL ACOSO SEXUAL EN LA RECOMENDACIÓN GENERAL 35 DEL CEDAW SOBRE LA VIOLENCIA POR RAZÓN DE GÉNERO CONTRA LA MUJER}

La Recomendación General 35 del CEDAW sobre la violencia por razón de género contra la mujer, por la que se actualiza la Recomendación General 19 (en adelante RG 19), presenta dos características generales a destacar por su trascendencia sobre el tema de estudio.

(I) La primera de ellas aparece delatada en su propia denominación. La Recomendación General 35 no deroga la RG 19, sino que la actualiza y complementa. Tal circunstancia seguramente obedece a que la RG 19 es un instrumento internacional de referencia para el desarrollo de las políticas públicas internas de los Estados parte del Convenio para la eliminación de todas las formas de discriminación contra la mujer (Nueva York, 1979). Y es que este Convenio no hace alusión a la violencia de género a pesar de ser el instrumento internacional básico sobre derechos de las mujeres. Fue la RG 19 de la CEDAW la que, interpretando el convenio, alcanzó la certera conclusión de que la violencia de género es una discriminación por razón de sexo. Derogar un instrumento internacional tan emblemático podría generar confusión e incluso freno en las políticas de los Estados parte.

Siendo esto así, a la RG 19 debemos acudir para corroborar que el acoso sexual es una manifestación de violencia de género. En ella se afirma que "la igualdad en el empleo puede verse seriamente perjudicada cuando se somete a las mujeres a violencia dirigida concretamente a ellas, por su condición de tales, por ejemplo, el hostigamiento sexual en el lugar de trabajo" (apartado 17 de la RG 19). Como quiera que la igualdad en el empleo se encuentra reconocida en el artículo 11 de la Convención para la eliminación de todas las formas de discriminación contra la mujer, la conclusión consiguiente es que el hostigamiento sexual es una vulneración del convenio.

A partir de esta afirmación, la RG 19 ofrece los elementos necesarios y suficientes sobre los cuales se podría contruir la definición de hostigamiento sexual cuando se afirma que "el hostigamiento sexual incluye conductas de tono sexual tal como contactos físicos e insinuaciones, observaciones de tipo sexual, exhibición de pornografía y exigencias sexuales, ya sean verbales o de hecho", además que "ese tipo de conducta puede ser humillante y puede constituir un problema de salud y de seguridad", y que "es discriminatoria cuando la mujer tiene motivos suficientes para creer que su negativa le podría causar problemas en relación con su trabajo, incluso con la contratación o el ascenso, o cuando crea un medio de trabajo hostil" (apartado 18 de la RG 19).

(II) La segunda de las caracteristicas generales a destacar por su trascendencia sobre el tema de nuestro estudio es que la Recomendación General 35 se inspira en los avances en la materia acaecidos, en los 25 años transcurridos desde la RG 19, en los ordenamientos jurídicos internos de los Estados parte y en instrumentos regionales de derechos humanos (entre los cuales se cita expresamente al Convenio de Estambul). De ahí precisamente su completa regulación (en comparación con la RG 19) que se fundamenta en las obligaciones de diligencia 
debida a los Estados partes en relación con la violencia por razón de género contra la mujer, y que, con base en ese fundamento, se desgrana en numerosas recomendaciones agrupadas en los siguintes apartados: medidas legislativas generales; prevención; protección; enjuiciamiento y castigo; reparaciones; coordinación; vigilancia y recopilación de datos; y cooperación internacional.

Al ser el acoso sexual una violencia de género, todas estas recomendaciones se le aplicarán, independientemente de si el acoso sexual se produce en el ámbito de una relación laboral, de cualquier otra relación contextual, o fuera de toda relación contextual. Como se verá seguidamente, lo anterior no ha impedido que, en el reparto habitual de papeles entre Naciones Unidas y la OIT, esta haya abordado la violencia de género en el trabajo, expresión en la cual se incluirá (como también se verá de seguido) el acoso sexual.

\section{EL ACOSO SEXUAL EN EL CONVENIO 190 DE LA OIT SOBRE VIOLENCIA Y ACOSO EN EL TRABAJO}

El Convenio 190 de la OIT sobre violencia $\mathrm{y}$ acoso en el trabajo no contiene un concepto de acoso sexual, aunque este se puede deducir, y no sin cierto trabajo, de su artículo 1 . En este se define la violencia y acoso en el mundo del trabajo como un conjunto de comportamientos y prácticas inaceptables, o de amenazas de tales comportamientos, ya sea que se manifiesten una sola vez o de manera repetida, que tengan por objeto, que causen o que sean susceptibles de causar, un daño físico, psicológico, sexual o económico. Dicho concepto incluye a la violencia y el acoso por razón de género, que se definen como aquellos que van dirigidos contra las personas por razón de su sexo o género, o que afectan de manera desproporcionada a personas de un sexo o género determinado, incluyendo en dicho concepto al acoso sexual.

De acuerdo con lo expuesto, el acoso sexual se podría definir como: (1) un conjunto de comportamientos y prácticas inaceptables, o de amenazas de tales comportamientos y prácticas, ya sea que se manifiesten una sola vez o de manera repetida, que tengan por objeto, que causen o que sean susceptibles de causar, un daño físico, psicológico, sexual o económico, (2) que van dirigidos contra las personas por razón de su sexo o género, o que afectan de manera desproporcionada a personas de un sexo o género determinado, y (3) con carácter sexual.

Una circunstancia adicional para acabar de delimitar el concepto de acoso sexual manejado en el Convenio 190 de la OIT viene dada por su laboralidad. El convenio no contempla todos los acosos, sino solo aquellos que ocurren durante el trabajo, en relación con el trabajo o como resultado del mismo, lo que incluye (según se dice en su artículo 3): (a) en el lugar de trabajo, inclusive en los espacios públicos y privados cuando son un lugar de trabajo; (b) en los lugares donde se paga al trabajador, donde este toma su descanso o donde come, o en los que utiliza instalaciones sanitarias o de aseo y en los vestuarios; (c) en los desplazamientos, viajes, eventos o actividades sociales o de formación relacionados con el trabajo (se trataría de acoso en misión); (d) en el marco de las comunicaciones que estén relacionadas con el trabajo, incluidas las realizadas por medio de tecnologías de la información y de la comunicación (se trataría del llamado acoso virtual, ciberbullying o ciberacoso); (e) en el alojamiento proporcionado por el empleador; y (f) en los trayectos entre el domicilio y el lugar de trabajo (se trataría de acoso in itinere).

El principio básico en el cual se fundamenta el Convenio 190 de la OIT es el de que todo Estado miembro que ratifique el convenio deberá respetar, promover y asegurar el disfrute del derecho de toda persona a un mundo del trabajo libre de violencia y acoso (artículo 4.1). De ahí se deriva la obligación de adoptar un enfoque inclusivo, integrado y que tenga en cuenta las consideraciones de género para prevenir $y$ eliminar la violencia y el acoso en el mundo del trabajo (artículo 4.2) en los siguientes términos:

- Que se adopte de conformidad con la legislación y la situación nacional y en consulta con las organizaciones representativas de empleadores y de trabajadores, lo que admite tanto un desarrollo legal en consulta con las organizaciones representativas de empleadores y trabajadores como un desarrollo a través de la negociación colectiva.

- Que se debería tener en cuenta la violencia $y$ el acoso que impliquen a terceros cuando proceda, lo que supone proteger 
frente a la violencia o el acoso procedentes de personas ajenas a la empresa, como pueden ser clientes, compradores, pacientes, usuarios, alumnos o familiares, público en general o proveedores de servicios. La expresión cuando proceda transmite la idea de que la prevención de la violencia y el acoso de terceros no procede en todo caso, sino solo en determinados casos, obviamente en trabajos que exigen relación con terceras personas ajenas a la empresa y paradigmáticamente en sectores como la sanidad, la asistencia social, la educación, las fuerzas de orden público o las prisiones.

- Que dicho enfoque consiste, en particular, en: (a) prohibir legalmente la violencia y el acoso; (b) velar por que las políticas pertinentes aborden la violencia y el acoso; (c) adoptar una estrategia integral a fin de aplicar medidas para prevenir y combatir la violencia y el acoso; (d) establecer mecanismos de control de la aplicación y de seguimiento o fortalecer los mecanismos existentes; (e) velar por que las víctimas tengan acceso a vías de recurso y reparación y a medidas de apoyo; (f) prever sanciones; (g) desarrollar herramientas, orientaciones y actividades de educación y de formación, y actividades de sensibilización, en forma accesible, según proceda; y $(\mathrm{h})$ garantizar que existan medios de inspección e investigación efectivos de los casos de violencia y acoso, incluyendo la actuación de la inspección del trabajo o de otros organismos competentes.

- Que, por cada Estado miembro, se deberán reconocer las funciones $\mathrm{y}$ atribuciones diferentes y complementarias de los gobiernos, de los empleadores y de los trabajadores, así como de sus organizaciones respectivas, teniendo en cuenta la naturaleza y el alcance variables de sus responsabilidades respectivas. Aquí el Convenio 190 de la OIT incide en la idea, que es totalmente compartible, de que todos los actores intervinientes en las relaciones laborales se deben comprometer con la erradicación de violencia y acoso.

A partir de este principio básico, obligatorio para los Estados parte, de respetar, promover y asegurar el disfrute del derecho de toda persona a un mundo del trabajo libre de violencia y acoso, y en consecuencia adoptar un enfoque inclusivo, integrado y que tenga en cuenta las consideraciones de género para prevenir y eliminar la violencia y el acoso en el mundo del trabajo, el Convenio 190 de la OIT desgrana unas obligaciones más concretas (en cuyo detalle no entraremos, invitando al lector o lectora a su lectura directa) que se refieren a protección y prevención (art. 7 a 9); a control de la aplicación y vías de recurso y reparación (art. 10); y a orientación, formación y sensibilización (art. 11).

Finalmente, es importante recordar que las disposiciones de la Recomendación 206 de la OIT complementan y se considerarán conjuntamente con las disposiciones del Convenio 190.

\section{EL CONCEPTO DE ACOSO SEXUAL EN EL DERECHO ESPAÑOL EN COMPARACIÓN CON LA NORMATIVA INTERNACIONAL}

La definición de acoso sexual contenida en el artículo 7.1 de la LO Igualdad se inspira en la definición de la Directiva 2006/54/CE y, en la medida en que el artículo 40 del Convenio de Estambul también se inspira en la definición dada por esa Directiva, podemos comprobar que la definición de acoso sexual contenida en el artículo 7.1 de la LO Igualdad coincide con la del Convenio de Estambul, si bien con la significativa diferencia, tanto respecto de la Directiva 2006/54/CE como respecto del Convenio de Estambul, de eliminar no deseado:

\footnotetext{
"Sin perjuicio de lo establecido en el Código Penal, a los efectos de esta Ley constituye acoso sexual cualquier comportamiento, verbal o físico, de naturaleza sexual que tenga el propósito o produzca el efecto de atentar contra la dignidad de una persona, en particular cuando se crea un entorno intimidatorio, degradante u ofensivo".
}

Muy positivamente ha recibido nuestra mejor doctrina científica la eliminación del no deseado. Así se ha argumentado que la insistencia histórica en el requisito conceptual de que la víctima de acoso sexual haya de demostrar de alguna forma que la actuación del sujeto activo le resulta indeseada, deriva de la inaceptable duda sobre la existencia de negligencia o culpa, cuando no previa provocación, por parte de la víctima: "este tipo de discursos no son en absoluto sostenibles 
ni jurisdiccionalmente ni socialmente en la actualidad"; "si una actuación resulta ofensiva, debe entenderse, sin sospechas de ninguna clase, que, por ello mismo, es indeseada"; "hacer referencia específica a la violación de la libertad y por tanto a la indeseabilidad del acoso sexual constituye un insulto a la víctima"18.

Dicho sea de paso, en la ley francesa (no podríamos afirmar que siguiendo a la española o llegando por sí misma a igual convencimiento) también se ha eliminado ${ }^{19}$.

\section{EL ACOSO SEXUAL COMO MANIFESTACIÓN DE DISCRIMINACIÓN SEXISTA Y DE VIOLENCIA DE GÉNERO}

La Ley Orgánica 1/2004 de 28 de diciembre, sobre Medidas de Protección Integral contra la Violencia de Género, solamente incluye dentro de su manto protector "la violencia que, como manifestación de la discriminación, la situación de desigualdad y las relaciones de poder de los hombres sobre las mujeres, se ejerce sobre estas por parte de quienes sean o hayan sido sus cónyuges o de quienes estén o hayan estado ligados a ellas por relaciones similares de afectividad, aun sin convivencia". O sea, la LO VioGen solamente protege contra la violencia en el ámbito de la pareja o de la expareja, pero no incluye las demás violencias de género, ni en particular el acoso sexual.

El Convenio de Estambul, las Recomendaciones Generales 19 y 35 de la CEDAW y el Convenio 190 de la OIT expresamente consideran el acoso sexual como violencia de género. Aquí se encuentra probablemente la principal carencia apreciada en el ordenamiento jurídico español en relación con estos instrumentos internacionales. Y se trata de una carencia que va más allá de lo meramente nominal pues en el derecho español la protección

18. Pérez del Río, M. T., La violencia ..., obra citada, pp. 20 y 32. 19. La Ley de 6 de agosto de 2012 relativa al acoso sexual introduce la siguiente definición de acoso sexual, y de situación asimilada al acoso sexual, sin que en ninguna de ellas aparezca la exigencia de ser "no deseado": "Le harcèlement sexuel est le fait d'imposer à une personne, de façon répétée, des propos ou comportements à connotation sexuelle qui portent atteinte à sa dignité en raison de leur caractère dégradant ou humiliant, ou créent à son encontre une situation intimidante, hostile ou offensante. Est également assimilé au harcèlement sexuel le fait, même non répété, d'user de toute forme de pression grave, dans le but réel ou apparent d'obtenir un acte de nature sexuelle, pour soi-même ou pour un tiers" (art. L. 1153-1 del Code du Travail). frente a la violencia de género a través de la LO VioGen es más amplia e intensa que la protección frente a la discriminación sexista a través de la LO Igualdad.

De catalogarse el acoso sexual, además de cómo discriminación sexista, también como violencia de género, entraría en el manto protector de la LO VioGen, lo que especialmente incidiría en la aplicación de unas mayores medidas de prevención, así como en mayor protección asistencial, sanitaria y social de las víctimas de acoso sexual. No es lo mismo que el acoso sexual se califique como discriminación sexista (lo que hace el artículo 7 de la LO Igualdad), que, sin dejar de calificarse como tal discriminación sexista, además se califique como violencia de género (lo que debería hacer el artículo 1 de la LO VioGen).

\section{LA SANCIÓN DEL ACOSO SEXUAL EN EL DERECHO ESPAÑOL FRENTE A LA NORMATIVA INTERNACIONAL}

Dentro de las tres opciones previstas en el Convenio de Estambul (recordémoslo: sanción penal; otras sanciones legales; sanción penal y otras sanciones legales), nuestro ordenamiento jurídico interno ha optado por la solución mixta de sanción penal para los casos más graves y para los demás casos sanciones diferentes a la penal. Por ello, la definición de acoso sexual contenida en el artículo 7.1 de la LO Igualdad expresamente se encabeza con un significativo "sin perjuicio de lo establecido en el Código Penal”, que permite concluir que hay dos conceptos de acoso sexual en nuestro ordenamiento jurídico interno: el más restringido concepto penal, que conduce a una sanción penal; y el más amplio recogido en el artículo 7.1 de la LO Igualdad, que conduce a sanciones distintas.

\subsection{Sanciones penales}

El Código Penal, aprobado a través de la Ley Orgánica 10/1995, de 23 de noviembre, introdujo un delito de acoso sexual en su artículo 184, cuya tipificación se amplió en la Ley Orgánica $11 / 1999$, de 30 de abril, y se retocó en la Ley Orgánica 15/2003, de 25 de noviembre. Según la redacción actualmente vigente del artículo 184 del Código Penal, hay un tipo básico (el que solicitare favores de naturaleza sexual, para sí o para un tercero, en el ámbito de una relación laboral, docente o de prestación de servicios, 
continuada o habitual, y con tal comportamiento provocare a la víctima una situación objetiva y gravemente intimidatoria, hostil o humillante), un subtipo agravado (si el culpable de acoso sexual hubiera cometido el hecho prevaliéndose de una situación de superioridad laboral, docente o jerárquica, o con el anuncio expreso o tácito de causar a la víctima un mal relacionado con las expectativas que aquella pueda tener en el ámbito de la indicada relación), y un subtipo agravatorio del tipo básico y del subtipo agravado (cuando la víctima sea especialmente vulnerable, por razón de su edad, enfermedad o situación).

A la vista del artículo 184 del Código Penal (y de la jurisprudencia recaída; en particular, la STS 1460/2003, de 7 de noviembre, el conocido como Caso Nevenka), el acoso sexual para constituir delito debe reunir, además de las condiciones establecidas con carácter general en el artículo 7.1 de la LO Igualdad, los cuatro siguientes requisitos típicos (que vienen así a configurar el mínimo ético que resulta exigido para la respuesta penal):

(1) La existencia de una solicitud de favores de naturaleza sexual, para sí o para un tercero, de manera que, aunque cualquier comportamiento verbal, no verbal o físico de carácter sexual puede constituir acoso sexual en el sentido del artículo 7.1 de la LO Igualdad, no todos esos comportamientos son delictivos en el sentido del artículo 184 del Código Penal, sino solo aquellos consistentes en una solicitud de carácter sexual, que la jurisprudencia, aunque admite cualquier expresión, exige que esta sea seria e inequívoca.

(2) La producción del comportamiento en el ámbito de una relación laboral, docente o de prestación de servicios (incluyendo dentro de esas relaciones la existente entre los componentes de una corporación local, Caso Nevenka), exigencia contenida en el artículo 184 del Código Penal que, sin embargo, no aparece en el artículo 7.1 de la LO Igualdad, donde no se exige ninguna contextualización de la conducta de acoso sexual.

(3) La existencia, consiguiente a la solicitud de favores de naturaleza sexual, de una situación objetiva y gravemente intimidatoria, hostil o humillante. Exigencia contenida en el artículo 184 del Código Penal que, comparada con la redacción del artículo 7.1 de la LO Igualdad, supone: en primer lugar, que no están comprendidos en el tipo penal cualesquiera comportamientos que, por su propósito o por su resultado, supongan un atentado a la dignidad de la persona, sino solo la solicitud de favores de naturaleza sexual, de una situación objetiva y gravemente intimidatoria, hostil o humillante; en segundo lugar, que, aunque existe similitud del tipo penal con la situación de creación de un entorno intimidatorio, degradante u ofensivo, aquel, por sus términos, exige aún mayor intensidad.

(4) En consonancia con todas las exigencias legales contenidas en el artículo 184 del Código Penal, se exige la intención para la comisión del delito, sin que se admitan las formas imprudentes. Esto frente al alcance del acoso sexual definido en el artículo 7.1 de la LO Igualdad, que no exige el propósito de atentar contra la dignidad de la persona, en cuanto que siempre bastaría que se alcance ese resultado (con independencia de cuál sea el propósito).

Conviene añadir que, además de los requisitos típicos anteriores, será necesario satisfacer una condición objetiva de perseguibilidad para proceder por delito de acoso sexual: la denuncia de la persona agraviada, de su representante legal o la querella del Ministerio Fiscal, que actuará ponderando los legítimos intereses en presencia. Si la víctima es menor de edad, incapaz o persona desvalida, bastará la denuncia del Ministerio Fiscal. Ahora bien, se aclara que el perdón del ofendido o del representante legal no extingue en estos delitos la acción penal ni la responsabilidad de tal clase (artículo 191 del Código Penal).

\subsection{Consecuencias dentro de la relación jurídica contextual}

Fuera del ámbito de aplicación del artículo 184 del Código Penal, será acoso sexual el así definido en el artículo 7.1 de la LO Igualdad, y, en el supuesto de estar contextualizado dentro de una relación jurídica (por ejemplo, el acoso laboral o en el empleo público; el acoso docente o el arrendaticio), se podrá acudir, para su sanción, a los mecanismos establecidos en su regulación para conductas incumplidoras. A los efectos expositivos, se puede distinguir entre aquellas relaciones jurídicas contextuales con regulación que contempla el acoso sexual, de aquellas otras que no lo contemplan.

(1) Con respecto a aquellas relaciones jurídicas contextuales con regulación que 
contempla el acoso sexual, la regulación más detallada es la relativa al acoso sexual laboral, que se encuentra expresamente considerado como el incumplimiento de un derecho de los trabajadores/as (artículo 4.2.e del Estatuto de los Trabajadores ${ }^{20}$ ), originando, dicho muy sucintamente, las siguientes consecuencias contractuales: la facultad empresarial de despedir disciplinariamente al acosador (artículo 54.2.g del ET); si la empresa, conociendo o debiendo conocer el acoso sexual, no actúa contra el acosador, la facultad del trabajador/a que ha sufrido el acoso de resolver el contrato de trabajo con la indemnización correspondiente a un despido improcedente (artículo 50 del ET); si la empresa genera represalias contra la víctima, la nulidad del despido (artículo 55.5 del ET); indemnización por vulneración de derechos fundamentales (artículos 182 y 183 de la Ley reguladora de la Jurisdicción Social).

Parecidamente, la protección frente al acoso sexual es un derecho de los empleados/as públicos (artículo 14.h del Estatuto Básico del Empleado Público ${ }^{21}$ ), y su realización se tipifica como una falta disciplinaria muy grave (artículo 95.2.b del EBEP).

Otro ejemplo de relación jurídica contextual con regulación que contempla el acoso sexual es la relación docente, pues, de acuerdo con la normativa legal aplicable, el acoso sexual en el ámbito docente debe ser tipificado en el plan de convivencia de los centros educativos como una falta muy grave con una medida correctora de expulsión temporal o definitiva (artículo 124.2 de la Ley Orgánica 2/2006, de 3 de mayo, de Educación).

(2) Con respecto a aquellas relaciones jurídicas contextuales con regulación que no contempla el acoso sexual, empiezan a surgir ciertos problemas

20. De conformidad con el artículo 4.2.e del Estatuto de los Trabajadores, "en la relación de trabajo, los trabajadores tienen derecho ... al respeto de su intimidad y a la consideración debida a su dignidad, comprendida la protección frente al acoso por razón de origen racial o étnico, religión o convicciones, discapacidad, edad u orientación sexual, y frente al acoso sexual y al acoso por razón de sexo".

21. De conformidad con el artículo 14.h del Estatuto Básico del Empleado Público, "los empleados públicos tienen los siguientes derechos de carácter individual en correspondencia con la naturaleza jurídica de su relación de servicio ... al respeto de su intimidad, orientación sexual, propia imagen y dignidad en el trabajo, especialmente frente al acoso sexual y por razón de sexo, moral y laboral". en orden a sancionar adecuadamente una conducta que se podría subsumir en el concepto de acoso sexual recogido en el artículo 7.1 de la LO Igualdad y en el artículo 40 del Convenio de Estambul.

En unos casos la laguna se podría llenar acudiendo a normas de carácter más general. Sería, por ejemplo, el caso del acoso sexual arrendaticio, pues el acoso sexual causado o tolerado por el arrendador no se contempla ni como justa causa de resolución del contrato de arrendamiento, ni como justificativo de una indemnización de daños y perjuicios, aunque la aplicación de las normas generales contenidas en el Código Civil sobre obligaciones recíprocas nos debería conducir a esas consecuencias (artículo 1124 del Código Civil).

En otros casos, la cobertura de la laguna se complica, en especial cuando se trata de la falta de contemplación del acoso sexual como infracción administrativa pues el principio de legalidad de las infracciones dificulta la solución. Sería el caso de la responsabilidad disciplinaria en la Carrera Judicial, pues ninguna infracción contempla el acoso sexual, y no es fácil incardinar la totalidad de los casos de acoso sexual en alguna de las infracciones tipificadas legalmente (véanse artículos 417 a 419 de la Ley Orgánica del Poder Judicial).

\subsection{Sanciones administrativas}

Las sanciones administrativas nunca se pueden superponer a las sanciones penales (principio de non bis in ídem). Pero sí se pueden superponer a las consecuencias jurídicas con fundamento en la relación jurídica contextual. Así, y sin perjuicio de las acciones que la víctima puede dirigir contra la empresa con fundamento en la relación laboral, es una infracción administrativa muy grave "el acoso sexual, cuando se produzca dentro del ámbito a que alcanzan las facultades de dirección empresarial, cualquiera que sea el sujeto activo de la misma" (artículo 8.13 de la Ley de Infracciones y Sanciones del Orden Social).

Fuera de los casos de existencia de una relación jurídica contextual, los problemas surgen cuando no existe una sanción administrativa general y no sea factible (dado el principio de legalidad de las infracciones) cubrir la laguna con normas más generales. La cuestión se concreta, muy 
particularmente, en el acoso sexual callejero y en el acoso sexual de personas extrañas. Se trata de conductas de difícil subsunción en delitos penales, sin encontrar tampoco una clara reprensión administrativa $^{22}$, y una posible reclamación de daños y perjuicios por responsabilidad civil extracontractual suena hoy a ciencia ficción.

\subsection{Prevención de la conducta de acoso sexual}

Aunque el Convenio de Estambul no establece normas particulares de prevención del acoso sexual, sí establece, en su Capítulo III, unas normas comunes de prevención de la violencia de género que, obviamente, son aplicables al acoso sexual. Dichas normas comunes de prevención de la violencia de género imponen a los Estados Parte obligaciones generales y específicas (a las que nos hemos referido sintéticamente en páginas precedentes). Particularmente, el Convenio 190 de la OIT establece obligaciones de prevención más intensas para las empresas cuando se trate de un acoso sexual laboral.

Nuestro ordenamiento jurídico interno contempla medidas de prevención del acoso sexual en la relación laboral y en el empleo público (artículos 48 y 62 de la LO Igualdad).

\section{CONCLUSIONES}

A la vista de la regulación sobre el acoso sexual contenida en el Convenio de Estambul, en la Recomendación General 35 de la CEDAW y en el Convenio 190 de la OIT, se aprecian interesantes mejoras en el arsenal normativo español contra el acoso sexual, entre ellas: la no contemplación del "no deseado" en la definición de acoso sexual contenida en el artículo 7.1 de la LO Igualdad; la graduación general de las sanciones entre penales y otras diferentes, que se deriva del artículo 184 del Código Penal; la regulación expresa que del

22. La Ley Orgánica 4/2015, de 30 de marzo, de protección de la seguridad ciudadana, tipifica como infracción leve "la realización o incitación a la realización de actos que atenten contra la libertad e indemnidad sexual, o ejecutar actos de exhibición obscena, cuando no constituya infracción penal" (art. 37.5). Dada la amplitud de la infracción y la habitual banalización de la violencia de género, no es claro que con esta infracción se vaya a sancionar todo comportamiento verbal, no verbal o físico de carácter sexual con el propósito o el efecto de atentar contra la dignidad de una persona. Lo adecuado sería considerar el acoso sexual según se define en el artículo 7.1 de la LO Igualdad como infracción autónoma. Solamente así se transmitirá la idea de ilicitud. acoso sexual se hace en algunos ámbitos, en especial en el ámbito laboral (artículos 4.2.e y 54.2.g del Estatuto de los Trabajadores), en el empleo público (artículos 14.h y 95.2.b del Estatuto Básico del Empleado Público), y en el ámbito docente (artículos 124.2 de la Ley Orgánica 2/2006, de 3 de mayo, de Educación); la obligación del empleador de adoptar medidas preventivas frente al acoso sexual laboral tanto en el empleo privado (artículo 48 de la LO Igualdad) como en las administraciones públicas (artículo 62 de la LO Igualdad).

Sin embargo, a la par de esas mejoras, igualmente se aprecian algunas carencias frente a la regulación sobre el acoso sexual contenida en el Convenio de Estambul, en la Recomendación General 35 de la CEDAW y en el Convenio 190 de la OIT. Así lo ha percibido también el Congreso de los Diputados de España, como se verifica con una lectura de los contenidos del Pacto de Estado en materia de Violencia de Género (2017).

(1) La más llamativa de las carencias se encuentra en la no consideración expresa del acoso sexual como violencia de género, a pesar que ello es claro en el Convenio de Estambul, en la Recomendación General 35 de la CEDAW y en el Convenio 190 de la OIT. Pues bien, los Grupos Parlamentarios firmantes del Pacto de Estado señalan (en la propuesta 86.3) la necesidad de declarar que son también formas de violencia contra las mujeres conforme al Convenio de Estambul (entre otras que se citan) el acoso sexual. De la anterior consideración se derivan importantes consecuencias, pues las medidas preventivas y el tratamiento de las víctimas son más intensas en el ámbito de la LO VioGen que en el ámbito de la LO Igualdad. Así es que los Grupos Parlamentarios firmantes del Pacto de Estado añaden (en la citada propuesta 86.3) que "la atención y recuperación, con reconocimiento de derechos específicos de las mujeres víctimas de cualquier acto de violencia contemplado en el Convenio de Estambul, y no previsto en la Ley Orgánica 1/2004, se regirá por las leyes específicas e integrales que se dicten al efecto de adecuar la necesidad de intervención y de protección a cada tipo de violencia". Con la finalidad de cubrir esta carencia de manera inmediata, se añade que, "hasta que se produzca este desarrollo normativo, las otras violencias de género reconocidas en el Convenio de Estambul, 
recibirán tratamiento preventivo y estadístico en el marco de la LO 1/2004".

(2) En el ámbito laboral, el Pacto de Estado propone "establecer la obligación de implantar medidas y protocolos contra el acoso sexual o el acoso por razón de género en las empresas, para mejorar la regulación y los derechos de las trabajadoras víctimas, abordando tal cuestión en la normativa de prevención de riesgos laborales" (propuesta 77). Causa esta propuesta una cierta perplejidad pues la obligación de prevenir el acoso sexual ya se contempla en los artículos 48 y 62 de la LO Igualdad. Cuestión diferente es que se mejore la aplicación de las normas vigentes, incluso reformándolas con vistas a unas mayores garantías de eficacia, pues no siempre se cumplen, o se cumplen solo formalmente, muchas veces con notables retrasos. Seguramente esta es la buena intención que está en el origen de la presente propuesta, y de ahí que a juicio del autor es así como se debe reinterpretar para potenciar el cumplimiento efectivo de la normativa que está ya vigente. Algo que, por lo demás, resultaría ser algo evidente desde el momento en que España ratificase (como esperemos que lo haga sin mucha demora) el Convenio 190 de la OIT.

(3) En el ámbito docente, el Pacto de Estado se detiene -a decir verdad- más atinadamente, acaso dada la trascendencia pública recientemente alcanzada por ciertas denuncias sobre acoso sexual en el ámbito universitario, y hace dos propuestas: "supervisar, por parte de la Inspección Educativa, los planes de convivencia y los protocolos de acoso escolar en los centros educativos, con el fin de identificar e incorporar actuaciones o indicadores de seguimiento relacionados con la violencia contra las mujeres" (propuesta 7); e "implicar a las Unidades de Igualdad de las Universidades en la realización de estudios sobre el impacto del acoso, las agresiones y los abusos sexuales en el ámbito universitario, y valorar, en su caso, la oportunidad de realizar campañas de prevención en los Campus Universitarios, y de forma particular de las agresiones sexuales en cita" (propuesta 8).
(4) En cuanto al acoso callejero, el Pacto de Estado contiene una propuesta un tanto timorata: "incluir nuevos baremos e indicadores en la Macroencuesta de la Delegación del Gobierno para la violencia de género, sobre todos los tipos de violencia sexual (y) recomendar a los diferentes observatorios la inclusión de dichos indicadores, con especial atención al llamado acoso callejero" (propuesta 188). O sea, se quiere analizar el alcance del problema del acoso callejero, se supone, como paso previo a adoptar medidas.

(5) El Pacto de Estado contiene una última propuesta sobre acoso sexual que vuelve a incurrir en imprecisiones técnicas: "incluir en la redacción del artículo 184 del Código Penal, una circunstancia específica en los delitos de acoso sexual, que debería contemplar el móvil de actuar por razones de género, atentando gravemente contra la dignidad de la mujer" (propuesta 95). $\mathrm{Y}$ es que el acoso sexual por su propia naturaleza ya supone actuar por razones de género, de ahí que contemplar un tipo agravado o una agravante por el móvil de actuar por razones de género es reiterativo. Cuestión diferente es que se mejore la tipificación y se agrave la penalidad, siendo seguramente esta la buena intención que está en el origen de la propuesta, siendo así como se debe reinterpretar.

En conclusión, y aunque la legislación española presenta aspectos muy positivos, el Convenio de Estambul, la Recomendación 35 de la CEDAW y el Convenio 190 de la OIT obligan a mejoras. El Pacto de Estado en materia de Violencia de Género ha asumido el testigo realizando una serie de propuestas en muchos casos muy atinadas en particular, la consideración del acoso sexual como manifestación de la violencia de género-, si bien también hay otras que, seguramente bien intencionadas, resultan perfectibles y deben reinterpretarse a la vista de esa intención. Queda ahora analizar y verificar cómo se plasman normativamente y cómo se aplican después las normas referidas por las administraciones implicadas. 


\section{REFERENCIAS BIBLIOGRÁFICAS}

- Aeberhard-Hodges, J., "Jurisprudencia reciente sobre el acoso sexual en el trabajo", Revista Internacional del Trabajo, volumen 115, número 6, 1996.

- Altés Tárrega, J. A., El acoso sexual en el trabajo, Editorial Tirant lo Blanch (Valencia, 2002).

- Del Rey Guanter, S., "Acoso sexual y relación laboral", Relaciones Laborales, Tomo Primero, 1993.

- Escudero Rodríguez, R., "La Ley 3/1989. Una reforma promocional de la mujer con acentuados claroscuros", Relaciones Laborales, Tomo Segundo, 1989.

- Gil Ruíz, J. M. (ed.), El Convenio de Estambul como marco de derecho antisubordiscriminatorio", Editorial Dykinson (Madrid, 2018).

- Husbands, R., "Análisis internacional de las leyes que sancionan el acoso sexual", Revista Internacional del Trabajo, volumen 112, número 1, 1993.

- Jacqmain, J., Harcèlement sexuel sûr le liux de travail: les moyens d'action juridiques en droit du travail, Ministerio de Empleo y Trabajo (Bruselas, 1992).

- - "L'égalité entre femmes et hommes dans les conditions de travail: amendements à la directive européenne 76/207", Contrats de Travail, número 276, Bruselas-Bélgica, 2003.

- Louis, M.V., Le droit de cuissage: France 1860-1930, Editions de l'Atelier (París, 1984).

- Lousada Arochena, J. F., El derecho de los trabajadores a la protección frente al acoso sexual, Editorial Comares (Granada, 1996).

- - "El concepto de acoso sexual laboral según la Sentencia de 13 de diciembre de 1999 del Tribunal Constitucional", Relaciones Laborales, número 3, 2000.

- - "El principio de transversalidad en el ámbito de las relaciones laborales (Un comentario de la Directiva 2002/73/CE, de 23 de septiembre de 2002)", Relaciones Laborales, Tomo Segundo, 2003.

- - El derecho fundamental a la igualdad efectiva de mujeres y hombres, Editorial Tirant lo Blanch (Valencia, 2014).

- Fundamentos del derecho a la igualdad de mujeres y hombres, Editorial Tirant lo Blanch México (México D.F., 2015).

- "El acoso sexual en el Convenio de Estambul y su transposición interna: El Pacto de Estado en materia de Violencia de Género", en Gil Ruíz, J. M. (ed.), El Convenio de Estambul como marco de derecho antisubordiscriminatorio", Editorial Dykinson (Madrid, 2018).

- MacKinnon, C., Sexual harassment of working women, Yale University Press (New Haven and London, 1979).

- Pérez del Río, M. T., "El acoso sexual en el trabajo: su sanción en el orden social", Relaciones Laborales, Tomo Segundo, 1990.

- La violencia de género en el ámbito laboral: el acoso sexual y el acoso sexista, Editorial Bomarzo (Albacete, 2009).

- Rubenstein, M., Informe sobre el problema del acoso sexual en los Estados miembros de las Comunidades Europeas, Oficina de Publicaciones Oficiales de las Comunidades Europeas (Luxemburgo, 1988).

- Rubio Castro, A. / Gil Ruiz, J. M. , Dignidad e Igualdad en derechos. El acoso en el trabajo, Dykinson (Madrid, 2012). 